\title{
Excitotoxic Degeneration Is Initiated at Non-Random Sites in Cultured Rat Cerebellar Neurons
}

\author{
Vytautas P. Bindokas and Richard J. Miller \\ Department of Pharmacological and Physiological Sciences, University of Chicago, Chicago, Illinois 60637
}

Prolonged stimulation of cultured cerebellar neurons by kainic acid (KA) leads to death of neurons first evident from the swelling of soma and neurites. Stimulation is accompanied by increases in $\left[\mathrm{Ca}^{2+}\right]_{i}$ and $\left[\mathrm{Na}^{+}\right]_{i}$ as monitored using digital imaging microfluorimetry. "Blebs" tended to form on neurites with the highest increases in $\left[\mathrm{Ca}^{2+}\right]_{j}$. Points of $\mathrm{Ca}^{2+}$ entry into neurites via glutamate-receptorgated channels predicted where approximately $80 \%$ of blebs would form tens of minutes later. These sites were close to neurite intersections where there was a high likelihood of synaptic contacts and were enriched in mitochondria as revealed by rhodamine 123 staining. $\mathrm{Ca}^{2+}$, but not $\mathrm{Na}^{+}$entry, produced a loss of mitochondrial potential. Prolonged KA, but not 50K, applications could fully dissipate the neuronal $\mathrm{Na}^{+}$gradient. Recovery of resting $\left[\mathrm{Na}^{+}\right]_{i}$ was delayed by $\mathrm{Ca}^{2+}$ loading. We propose that blebs form at certain synaptic regions due to localized ionic fluxes and local $\mathrm{Ca}^{2+}$ overloading. Increased $\left[\mathrm{Ca}^{2+}\right]_{i}$ may hamper restoration of normal $\left[\mathrm{Na}^{+}\right]_{i}$ permitting local osmotic swelling as well as activation of $\mathrm{Ca}^{2+}$-dependent enzymes and other processes. $\mathrm{Na}^{+}$may slow, block, or reverse $\mathrm{Na} / \mathrm{Ca}$ exchange and enhance swelling. These conditions could not be reproduced by global changes in ion concentrations produced by $\mathrm{Ca}^{2+}$ or $\mathrm{Na}^{+}$ionophores. The earliest stages of excitotoxicity thus appear to be manifestations of localized disruptions of ionic homeostasis mediated by $\mathrm{Ca}^{2+}$ overload and $\mathrm{Na}^{+}$influx.

[Key words: glutamate receptors, calcium homeostasis, sodium homeostasis, bleb formation, varicosity, Purkinje neuron, Fura 2, SBFI, rhodamine 123, mitochondria]

The molecular basis of neuronal death following overactivation of glutamate receptors ("excitotoxicity") is still unclear in spite of intensive research on this subject. The death of neurons under these circumstances is typified by loss of ionic homeostasis, swelling, and rapid loss of membrane integrity. It is widely believed that an increase in $\left[\mathrm{Ca}^{2+}\right]_{i}$ is one of the major triggers for these events (cf. Choi, 1988, 1992). Indeed, increases in $\left[\mathrm{Ca}^{2+}\right]_{i}$ are invariably observed following activation of neuronal glutamate receptors. Nevertheless, it has also been suggested that

\footnotetext{
Received Mar. 13, 1995; rcviscd Junc 22, 1995; accepted June 23, 1995.

We thank Dr. James R. Brorson for providing cultures of cerebellar neurons. Dr. David Bleakman (Lilly Research, Windlesham UK) assisted in some initial experiments. This work was funded by NIH Grants DA 02121, DA02575, and MH40165 to R.J.M.

Correspondence should be addressed to Richard J. Miller, Wm. Mabie Professor of Neuroscience, Department of Pharmacological and Physiological Sciences, University of Chicago, 947 East 58th Street, Chicago, IL 60637.

Copyright (C) 1995 Society for Neuroscience $0270-6474 / 95 / 156999-13 \$ 05.00 / 0$
}

these rises are unrelated to the process of excitotoxicity (cf. Choi, 1988). It is certainly quite clear that there is no simple correlation between global measures of neuronal $\left[\mathrm{Ca}^{2+}\right]_{i}$ following glutamate receptor activation and the propensity of a neuron to die. Nevertheless, recent studies showing that neurons can be protected from excitotoxicity by $\mathrm{Ca}^{2+}$ buffers clearly indicate that increases in $\left[\mathrm{Ca}^{2+}\right]_{i}$ are involved in these processes (e.g., Tymianski et al., 1993b). It also seems clear that not all $\left[\mathrm{Ca}^{2+}\right]_{\text {, }}$ is equally effective in causing neuronal death (Dubinsky and Rothman, 1991; Tymianski et al., 1993a). This may indicate that it is not only the fact that $\left[\mathrm{Ca}^{2+}\right]_{i}$ increases, but how, and where, it increases within the cell that is important. The movement of other ions such as $\mathrm{Na}^{+}$, or $\mathrm{Cl}^{-}$may also influence events in excitotoxicity (Rothman, 1985; Dessi et al., 1994). Also unclear are the molecular events that are triggered by a rise in $\left[\mathrm{Ca}^{2+}\right]_{i}$ that ultimately cause the death of the neuron. Activation of proteases, phospholipases, the production of toxic free radicals, and impairment of mitochondrial function have all been suggested

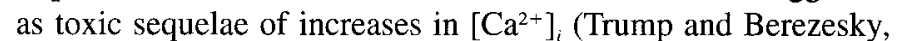
1992).

One of the earliest signs of compromised cellular vitality is the formation of blister-like swellings of the membrane (bleb formation) and swelling of the soma. Bleb formation has been regarded as both an irreversible and reversible stage in cell death (Gabai et al., 1990; Harman et al., 1990; Friedman and Haddad, 1994). Bleb formation in numerous preparations has been investigated in detail. It has been linked to increases in $\left[\mathrm{Ca}^{2+}\right]_{i}$ (Jewell et al., 1982; Tsai et al., 1988; Phelps et al., 1989) but may occur independently of such a rise (Nieminen et al., 1990). Blebs are generated when cellular ATP levels are depleted during anoxia or block of synthetic pathways (Gabai et al., 1990; Florine-Casteel et al., 1991; Jurkowitz-Alexander et al., 1992) and when cytoskeletal elements, especially $\mathrm{F}$-actin, are altered (Nicotera et al., 1986; Watanabe and Phillips, 1986; Malorni et al., 1991; Kuhne et al., 1993). Blebs also form in response to free radicals and free radicals can inhibit ATP generation, disrupt the cytoskeleton, and directly affect lipid and protein structure and $\left[\mathrm{Ca}^{2+}\right]_{i}$ (Mirabelli et al., 1988; Scott et al., 1989; Burton et al., 1990; Malorni et al., 1991). Stimulation of neuronal glutamate receptors is known to induce swelling of somas and dendrites (e.g., Olney et al., 1979; Sloviter and Dempster, 1985; Peterson et al., 1989) and has recently been shown to produce $\mathrm{Na}^{+}$-dependent blebs in acutely isolated hippocampal neurons (Friedman and Haddad, 1993).

The goals of the present study were to determine if some of the earliest stages of excitotoxicity such as blebs are spatially related to points of $\mathrm{Ca}^{2+}$ entry following stimulation of glutamate receptors. Changes in $\left[\mathrm{Na}^{+}\right]_{i}$ in the soma were likewise 
7000 Bindokas and Miller - Excitotoxic Damage Initiates at Non-Random Sites
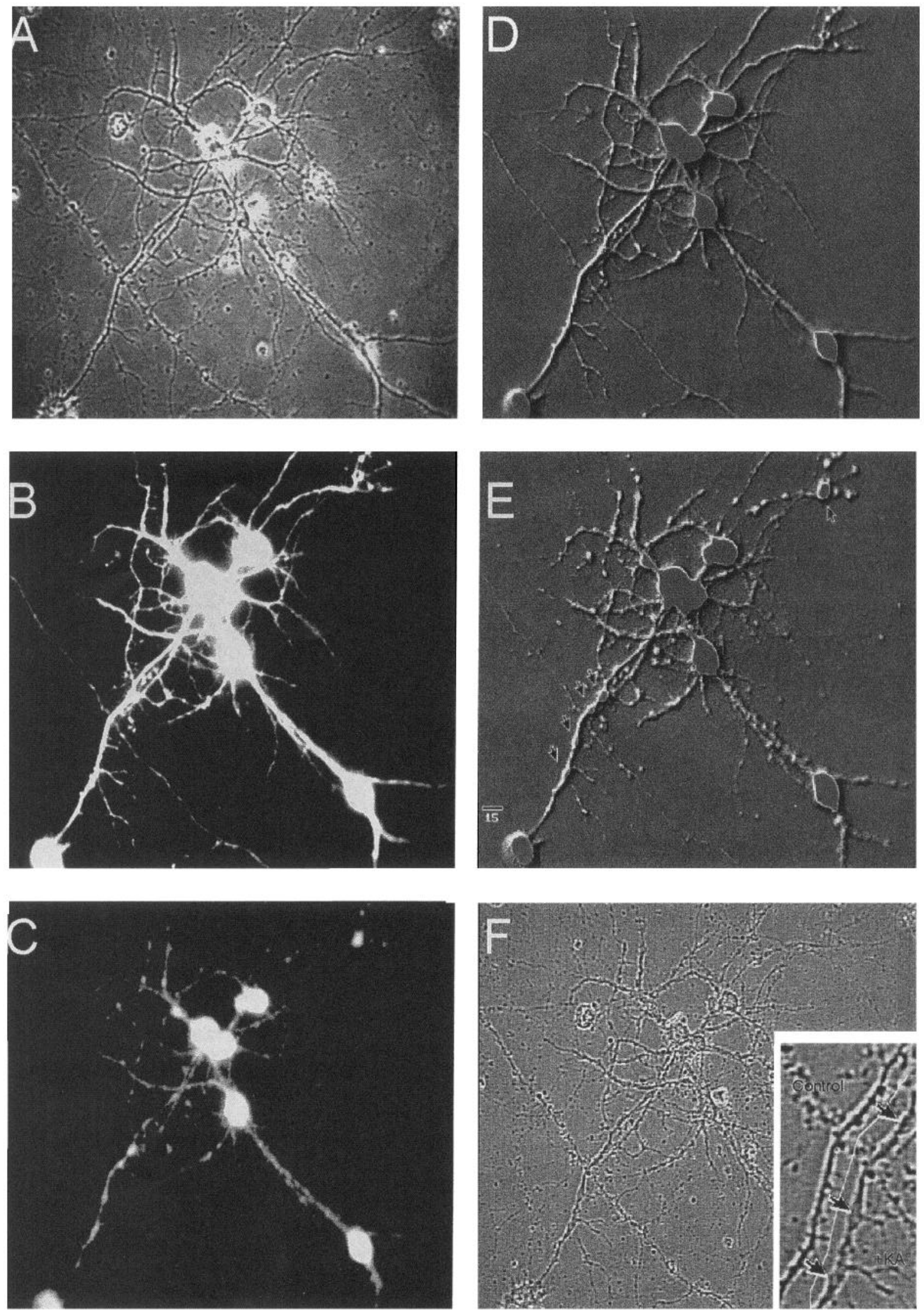

Figure 1. Application of KA initially produces localized disruptions of ionic homeostasis manifested by growth of varicosities or "blebs" on dendrites. A, Phase-contrast image of cerebellar neurons. Cell at lower left has Purkinje-like morphology; all cells have smooth neurites. Note the extensive network of neurites. Cells are $19 \mathrm{~d}$ in vitro. B, Baseline morphology of cultured cerebellar neurons as seen in fluorescence emission 
investigated. The effect of these disturbances on mitochondrial potential indicate that $\mathrm{Ca}^{2+}$ entry depolarizes mitochondrial potential. Our results demonstrate the spatially heterogeneous nature of $\mathrm{Ca}^{2+}$ entry and show that this is closely related to points of induction of neuronal degeneration.

Preliminary results of some of the experiments have appeared in an abstract (Bindokas et al., 1993).

\section{Materials and Methods}

Cerebellar cultures enriched in Purkinje cells have been described previously (Brorson et al., 1991). Briefly, neurons are dissociated from rat embryos (day E16), plated onto poly-L-lysine-coated, $15 \mathrm{~mm}$ glass coverslips, and maintained above a layer of astrocytes. Some cells attain Purkinje-like characteristics after 14-21 d in vitro (D.I.V.), and remain viable for up to several months. Cultures are devoid of granule cells. Most cells used in studies reported herein were approximately 24 D.I.V. (range 12-41 D.I.V.). Cells were loaded with fura 2 AM ( 3 or $5 \mu \mathrm{M}$ ) for $15 \mathrm{~min}$ at $37^{\circ} \mathrm{C}$, and allowed at least $30 \mathrm{~min}$ of wash to complete deesterification of the calcium indicator dye. Coverslips were then often split to yield multiple samples from the same source coverslip. Some cells were loaded with $100 \mu \mathrm{M}$ fura-2 salt via patch pipette (Toth et al., 1993) to limit $\left[\mathrm{Ca}^{2+}\right]_{i}$ measurements to postsynaptic loci. The sample chamber was superfused with saline, or test solutions, at a rate of 1.5 Inl//nin by a gravity-feed system, except for fast data sampling (see below). Saline contained (in mM): $144 \mathrm{NaCl}, 10 \mathrm{HEPES}, 2 \mathrm{CaCl}_{2}, 1$ $\mathrm{MgCl}_{2}, 5 \mathrm{KCl}, 10 \mathrm{D}$-glucose; set to $\mathrm{pH} 7.4(\mathrm{NaOH})$ and $312 \mathrm{mOsm}$. Calcium-free saline was made by replacing $\mathrm{CaCl}_{2}$ with $\mathrm{MgCl}_{2}$ and adding $0.1 \mathrm{mM}$ EGTA. Sodium-free saline was made by replacing $\mathrm{NaCl}$ by $150 \mathrm{~mm} \mathrm{~N}$-methyl-D-gluconate or TEA-Cl. $\mathrm{CoCl}_{2}(2 \mathrm{mM})$ was added to some $\mathrm{Na}^{+}$-free salines (see Fig. $6 \mathrm{C}$ ). Saline with $50 \mathrm{~mm} \mathrm{KCl} \mathrm{(50K)}$ was made by replacing an equivalent amount of $\mathrm{NaCl}$. Salines differed hy no more than $3 \mathrm{mOsm}$. All experiments were conducted at $22-24^{\circ} \mathrm{C}$.

Free calcium concentration in neurons, $\left[\mathrm{Ca}^{2+}\right]_{i}$, was calculated by digital video microfluorimetry using an intensified CCD camera as previously described (Bindokas et al., 1993). At intensifier gains required to image neurites the signal from somas was at saturation and precluded comparison of changes in somas versus neurites. For capturing the initial $\mathrm{Ca}^{2+}$ entry points, the $50 \mathrm{~K}$ or $200 \mu \mathrm{M}$ kainate (KA) salines were applied by a fast U-tube perfusion system (cf. Fenwick et al., 1982) controlled by computer ( 2.5 or $5 \mathrm{sec}$ duration applications) while saving images to RAM for subsequent off-line analysis. Head pressure for the $\mathrm{U}$ tube was kept constant. The imaging system was used to typically average 8 frames at each wavelength and could generate ratio images at $1.7 \mathrm{~Hz}$. Fluorescence intensity was always optimized (using $\mathrm{Ex}_{380 \mathrm{~nm}}$ ) at the start of each experiment for the major dendrite of interest. This could result in inadequate signal in the finest neurites. These cases produced null data if either excitation wavelength was below low-cutoff threshold or at best noisy records. $\left[\mathrm{Ca}^{2+}\right]_{i}$ was calculated from conventional $\mathrm{f} 340 / \mathrm{f} 380$ ratios. Calcium entry maps (see Figs. $3 C, 6 C$ ) were made by thresholding the ratio image at the first instance of the $\mathrm{Ca}^{2+}$ rise for a KA application to identify the pixels with the highest values and then superimposing this image onto the fluorescence image obtained at 380 or $340 \mathrm{~nm}$ excitation. The spatial limits depended on the particular lenses used in a experiment. The pixel dimensions form the practical limit of resolution in ratio images. Many images are obtained with a pixel size of roughly $0.5 \mu \mathrm{m}$. The highest resolution was with NA 1.3 objectives and a pixel size of $0.13 \mu \mathrm{m}$. The signal averaging and thresholding largely minimized random pixel noise. The technique of ratioing ratios further minimized random fluctuations by virtue that only pixels present in each ratio were actually divided. The shortest distance from bleb edge to the edge of an initial $\mathrm{Ca}^{2+}$ entry site was measured along the intervening neurites using a calibrated cursor rou- tine in the IMAGE1 software package. Where a $\mathrm{Ca}^{3+}$ cntry sitc touched a bleb, the distance was scored as zero.

Blebs on neurites could be detected using phase-contrast microscopy (e.g. Figs. $1 F, 5 A$ ), however, they were often difficult to demonstrate in images due to low contrast. Since bleb cytosol contained fura 2 , they were especially prominent in fluorescence images. Enhanced resolution of neurite morphology (see Figs. 1, 2, 3, 7) was obtained using UV fluorescence images (Ex 340 or $380 \mathrm{~nm}$ ) of fura-2-filled cells by digital filtering using "sharpen" followed by "unsharp masking" within the IMAGE-1 software package (Universal Imaging, West Chester, PA). Unsharp mask filtering is commonly used for enhancing existing detail in satellite images, etc. (cf. Pratt, 1991). Enhancement of faint details and edges within the images were obtained by subtracting $95-100 \%$ of a low-pass, blurred version of the image (typically using a $5 \times 5$ to $8 \times 8$ kernel). All images in a series were processed identically. The process moved intensity values towards middle gray while retaining brightness information and further contrast enhancement was obtained by stretching the resultant intensity range to span 256 levels.

Mitochondria were stained with rhodamine $123(\mathrm{R} 123 ; 10 \mu \mathrm{g} / \mathrm{ml})$ for 1 min. R123 intensity stains mitochondria selectively by virtue of, and according to, their transmembrane potential (Duchen and Biscoe, 1992). The dye fluorescence was typically stable within neurons for over 10 hr. Images were obtained using standard rhodamine optics (excitation 510-560, DM580, emission > 590; Nikon). Rhodamine filters completely excluded signal from fura 2 and vice versa. Fluorescence intensity was colorized in some images (Fig. 7) to improve discrimination of intensity values.

Synaptic regions were identified by staining with the styryl dye RH$414(30 \mu \mathrm{M})$ in $50 \mathrm{~K}$ saline for $2 \mathrm{~min}$. Images werc obtaincd using standard rhodamine optics. Some cells were post-fixed, treated with anti-synaptophysin primary antibody (DAKO, Carpinteria, CA.), and visualized with an AMCA-conjugated secondary antibody (Jackson Immunoresearch, West Grove, PA).

Intracellular sodium concentration, $\left[\mathrm{Na}^{+}\right]_{i}$, was determined using the ratiometric dye, sodium-binding benzofuran isophthalate (SBFI; Molecular Probes) (Minta and Tsien, 1989) with identical imaging methods as for fura 2. Cultures were loaded with $10 \mu \mathrm{M}$ SBFI plus $12.25 \%$ pluronic F-127 for $1 \mathrm{hr}$ at $37^{\circ} \mathrm{C}$ and followed by $30 \mathrm{~min}$ wash. At the end of each experiment calibration was made with $5 \mu \mathrm{M}$ gramicidin $\mathrm{D}$ (Sigma) (Negilescu et al., 1990) and standards $(0,20,40,80,160 \mathrm{~mm}$ $\mathrm{Na}^{+}$). Calibration parameters were individually fit to mean ratios in each standard for each cell, and individual calibration curves were utilized to convert ratio data to $\left[\mathrm{Na}^{+}\right]_{i}$ for each cell.

\section{Results}

Cultures of cerebellar neurons used in these studies are enriched in Purkinje-like neurons. Granule cells are absent. Most neurons are GABAergic and possess receptors that are sensitive to AMPA and kainate, but not to NMDA (Brorson et al., 1993, 1994). Kainate-induced excitotoxicity has been shown to be caused by the activation of AMPA receptors and largely $\mathrm{Ca}^{2+}$ dependent (Brorson et al., 1994).

\section{Changes in $\left[\mathrm{Ca}^{2+}\right]_{\mathrm{i}}$}

Prolonged stimulation (10-30 min) of cerebellar neurons with kainate $(200 \mu \mathrm{M})$ resulted in swelling of somas and neurites followed by degeneration. Examples of excitotoxic degeneration in cells with diverse morphologies are shown in Figures 1-3. In cases where large increases in $\left[\mathrm{Ca}^{2+}\right]_{i}$ within neurites were observed, localized swellings ("blebs") occurred at various points

intensity of fura-2 loaded cells (Ex $380 \mathrm{~nm}$; see Materials and Methods). C, Same field 30 min after application of $200 \mu \mathrm{M}$ KA shows swelling of somas and uneven swelling of dendrites. Intensity of the Ex $380 \mathrm{~nm}$ fluorescence has decreased indicating $\left[\mathrm{Ca}^{2+}\right]_{i}$ has increased. $D$, The image in $B$ has been digitally sharpened and unsharp masked to enhance detail. This procedure produces a similar image sharpening as digital deconvolution and enhances detection of faint structures (see Materials and Methods). Somas appear flat-topped due to camera saturation. The intense signal from the six neuronal somas has limited the camera gain and thus the signal from small neurites. A greater enhancement is possible in higher magnification images as in Figure 2 or where intensity ranges are less extreme as in subsequent figures. $E$, Digital enhancement of image in $C$. Arrows indicatc some of the blebs that have formed after KA treatment. $F$, Phase contrast image corresponding to $C$ and $E$. Higher magnification of the neurite is shown in the inset at the right. Arrows illustrate some of the blebs that formed on the neurite after KA treatment. Scale $A-F=15 \mu \mathrm{m}$. 

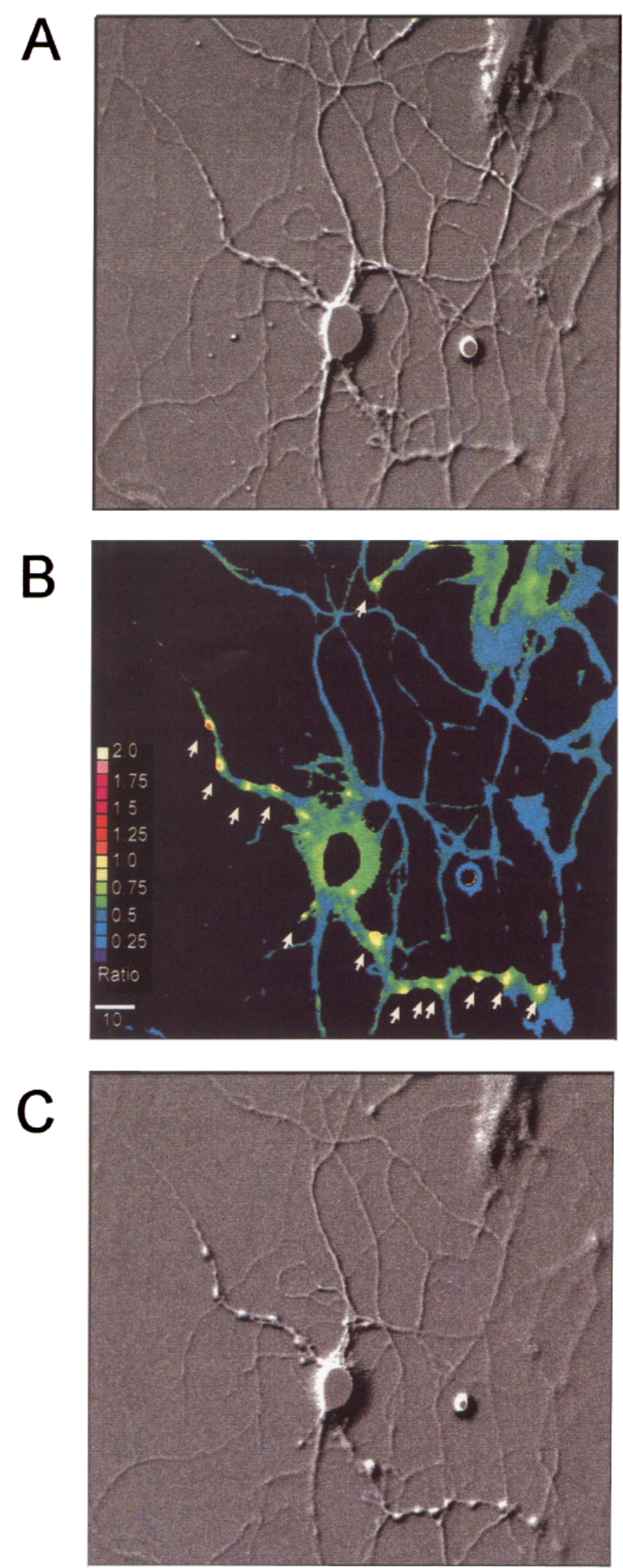

and the neurites took on a beaded appearance (cf. Figs. $1 F, 3 E$ ). In extreme cases, the neurites appeared to break apart. These changes typically began 10-30 min following onset of KA application. Neurites that displayed only small changes in $\left[\mathrm{Ca}^{2+}\right]_{i}$ usually did not develop these morphological changes (Fig. 2). Once formed, blebs continued to increase in volume, but in some cases shrank and were resorbed. Bleb growth was greatest in $\mathrm{Na}^{+}$-containing solutions (see below).

Blebs appeared to form at sites exhibiting the highest initial $\left[\mathrm{Ca}^{2+}\right]_{i}$ rises following the application of kainate. In the example in Figure 2, the blebs are closely correlated with the regions that showed the highest initial increases in $\left[\mathrm{Ca}^{2+}\right]_{i}$ (red, yellow pixels) immediately after application of KA ( 1 min time point

$\leftarrow$

Figure 2. Blebs tend to only form in neurites exhibiting a large rise in $\left[\mathrm{Ca}^{2+}\right]_{i} . A$, Control image derived from fura-2 emission (Ex $380 \mathrm{~nm}$ ) by digital filtering. $B, \mathrm{f} 340 / \mathrm{f} 380$ ratio image taken $1 \mathrm{~min}$ after initiation of $\mathrm{KA}$ application $(200 \mu \mathrm{M})$ shows $\left[\mathrm{Ca}^{2+}\right]_{i}$ rise was restricted to only a few neurites and that the rise in $\left[\mathrm{Ca}^{2+}\right]_{i}$ was also nonuniform within those neurites. The regions with the greatest increases in $\left[\mathrm{Ca}^{2+}\right]_{i}(\mathrm{red}$, yellow) occurred primarily in two neurites of the cell shown at the center of the image as well as in a neurite at the top of the field. Signal from the soma regions of this neuron and glia at the top of the field saturated the camera and appear black in this image. Ratio color code is shown on the left. $C$, Blebs formed ( $8 \mathrm{~min}$ after start of $\mathrm{KA}$ ) only on the neurites with large rise in $\left[\mathrm{Ca}^{2+}\right]_{i}$. Note the blebs in the neurite at the top of the field, that blebs are also associated with neurite intersections, and with regions that exhibited the highest $\left[\mathrm{Ca}^{2+}\right]_{i}$. Peaks in the $\left[\mathrm{Ca}^{2+}\right]_{i}$ predicted well the sites where blebs would later form. Similar results were observed where only one neuron was filled with fura- 2 salt by means of a patch pipette (data not shown). Scale bar, $10 \mu \mathrm{m}$.

Figure 3. Maps of initial rises in $\left[\mathrm{Ca}^{2+}\right]_{i}$ effectively predict where most blebs will form. A, Baseline digitally filtered fura image (Ex 380) shows two dendrites on left with elaborate contacts with intersecting axon-like neurites (open arrows), and another neurite (solid arrows) that appears to overlie the axons, forming only simple contacts. $\left[\mathrm{Ca}^{2+}\right]_{i}$ rises in regions labeled $a-d$ are shown in $D$, below. $B$. Ratio map of $\left[\mathrm{Ca}^{2+}\right]$ rises obtained at the instance of fast application of KA indicates nonuniform increase in left neurites (arrows; warm-colored pixels), but not in right neurites. KA was applied in Na-free saline in the presence of TTX and TA3090, a broad-spectrum $\mathrm{Ca}^{2+}$-channel blocker (see Materials and Methods). Note that initial rise loci are associated with neurite intersections (arrows), and that $\left[\mathrm{Ca}^{2+}\right]_{i}$ did not rise in the neurite with simple contacts. Both neurites were able to produce a rise in $\left[\mathrm{Ca}^{2+}\right]_{i}$ in response to $50 \mathrm{~K}$ application (data not shown). Color scale codes the fold increase in ratio above initial value ( $0-7$-fold). Scale bar for A-C, $5 \mu \mathrm{m}$. $C$, At $20 \mathrm{~min}$ following KA exposure, the dendrites with elaborate neurite intersections display prominent blebs; the neurite with few apparent contacts appears unaltered. $D$, Complete record of $\left[\mathrm{Ca}^{2+}\right]_{i}$ for regions indicated in $A(a-d)$. The neurite that produced blebs (regions $a$ and $b$ ) and swelling shows an immediate and sustained rise (heavy lines) in $\left[\mathrm{Ca}^{2+}\right]_{i}$ upon application of KA. The other neurite (regions $c$ and $d$ ) shows little response (dotted traces). E, Following KA treatment this neuron has produced prominent blebs (red overlay) in close association with neurite crossing points, especially axon-like neurites (arrows). The image consists of the overlay of the initial and final digitally processed fura images (green and red, respectively; Ex $340 \mathrm{~nm}$ ). Arrows indicate some examples of the blebs that formed at neurite intersections. Scale bar, $10 \mu \mathrm{m}$. $F$, Histogram comparing the distribution of distances of blebs to the nearest neurite intersection (dark bars) with the distances between each neurite and its nearest neighboring neurite (open bars) for example in $A-D$. Most blebs formed over neurite cross points (33 of $39=84 \%$ ), indicating that bleb distribution was non-random. Had the blebs formed randomly, their distribution was expected to be centered as a Gaussian about half the mean distance between each neurite and its nearest neighboring neurite (bell curve). This is clearly not the case. 

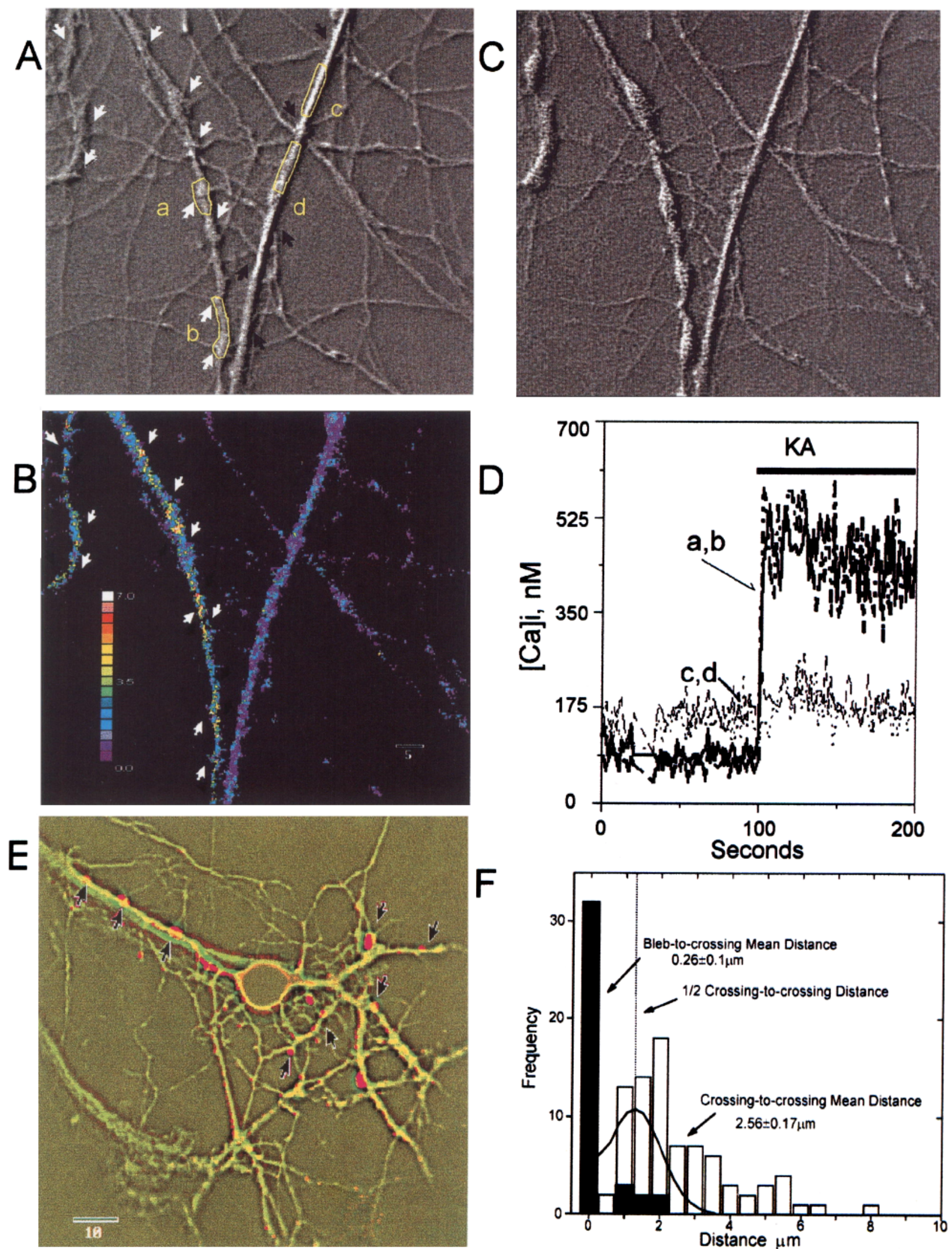
shown in Fig. 2B). These peaks effectively predicted where blebs formed up to tens of minutes later. Note that most of the $\mathrm{KA}$-induced peaks in $\left[\mathrm{Ca}^{2+}\right]_{i}$ can be lined up with bleb loci in Figure $2 C$. Similar results were observed in neurons filled with fura 2 salt by means of a patch pipette, thus limiting the fluorescence signal to the postsynaptic neurites (data not shown). By measuring the distance of each resulting bleb to the initial peaks in $\left[\mathrm{Ca}^{2+}\right]_{i}$ rises in 7 cells, it was determined that 102 of 123 blebs $(83 \%)$ exactly overlapped the peak loci. The remaining 21 blebs formed within $3.1 \pm 0.5 \mu \mathrm{m}$ of initial peak loci.

There did not appear to be a specific critical value for bleb initiation in terms of the peak $\left[\mathrm{Ca}^{2+}\right]_{i}$ initially attained. Some blebs formed on neurites too thin for accurate determination of associated $\left[\mathrm{Ca}^{2+}\right]_{i}$ rises or entry patterns. In general, if average $\left[\mathrm{Ca}^{2+}\right]_{i}$ initially reached roughly $700 \mathrm{nM}$, then blebs could form. However, in some cells no blebs formed despite $\left[\mathrm{Ca}^{2+}\right]_{i}$ exceeding $1 \mu \mathrm{M}$. Bleb resorption was occasionally noted, however, once formed blebs increased in volume in $\mathrm{Na}^{+}$-containing solutions. Since blebs could form in $\mathrm{Ca}^{2+}$-free saline (see below), $\mathrm{Ca}^{2+}$ was only one factor in bleb formation.

When applied in normal, $\mathrm{Na}^{1}$-containing medium, kainate depolarizes neurons. $\mathrm{Ca}^{2+}$ entry under these circumstances involves influx through both voltage-sensitive $\mathrm{Ca}^{2+}$ channels and glutamate receptor-gated ionophores (Brorson et al., 1993, 1994). The component of $\mathrm{Ca}^{2+}$ entry directly through AMPA receptors can produce excitotoxicity in these neurons (Brorson et al., 1994). We also mapped $\mathrm{Ca}^{2+}$ entry selectively through glutamate-gated channels by applying $\mathrm{KA}$ in $\mathrm{Na}^{+}$-free saline plus the nonspecific voltage-sensitive calcium channel blocker TA3090 (Bleakman et al., 1991; Brorson ct al., 1993) and TTX, or by monitoring the quench of fura 2 by $\mathrm{Co}^{2+}(\mathrm{Ex} 340 \mathrm{~nm})$. $\mathrm{Co}^{2+}$ will permeate non-NMDA receptor channels that are $\mathrm{Ca}^{2+}$ permeable, but not voltage-gated $\mathrm{Ca}^{2+}$ channels (Pruss et al., 1991). Initial patterns for KA-gated increases in $\left[\mathrm{Ca}^{2+}\right]_{i}$ under these conditions were also non-uniform and were usually associated with neurite intersections. In the example shown in Figure $3 A$, the neurite on the left (solid arrows) exhibited numerous elaborate contacts with axon-like neurites while the large neurite on the right (black, solid arrows) showed few contacts and instead appears to lie over the bedding of neurites. $\mathrm{Ca}^{2+}$ entry maps (Fig. $3 B, D$ ) showed that $\left[\mathrm{Ca}^{2+}\right]_{i}$ rose only in the left neurite with KA application (yellow, red, white pixels). Note that blebs only formed in the left neurite where close neurite contacts and rapid $\left[\mathrm{Ca}^{2+}\right]_{i}$ rises are evident (Fig. $3 B-D$ ). $\left[\mathrm{Ca}^{2+}\right]_{i}$ information for the finest neurites is scant due to faint fura signal. The close association of blebs on a dendritic-like process with axon-like intersections is further illustrated in Figure $3 E$. Mapping of the distances between blebs and the nearest neurite intersection in this example reveals that $84 \%$ of all blebs formed at intersections where neurites were closely opposed (Fig. $3 F$ ). The distribution of bleb-to-intersection distances compared to the distance of each neurite intersection with its nearest neighboring intersection was non-random. If the blebs occurred randomly, then the blebto-intersection distances should have a Gaussian distribution centered about half the mean distance between adjacent intersections. This was clearly not the case. Overall, 166 of 215 blebs ( $77 \%$ ) formed at neurite intersections ( $n=6$ preparations), and the mean distance of blebs to neurite intersections was $0.4 \pm$ $0.1 \mu \mathrm{m}$ compared to a mean intersection-to-intersection distance of $4.2 \pm 0.9 \mu \mathrm{m}$.

Blebs sometimes formed following $\mathrm{KA}$ application in $\mathrm{Ca}^{2+}$ free saline ( 9 of 13 experiments). Blebs that formed did so at
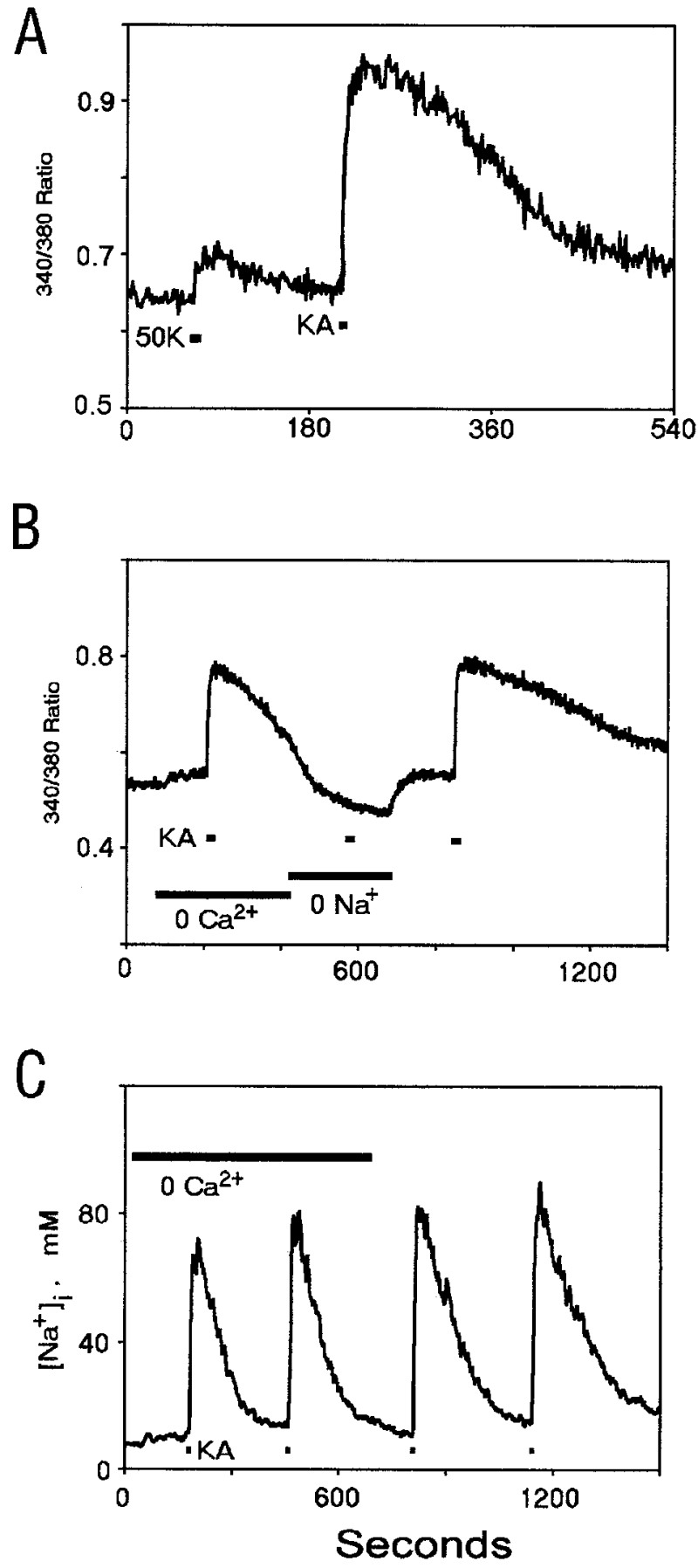

Figure 4. Brief KA applications produced long duration changes in $\left[\mathrm{Na}^{+}\right]_{i} \cdot\left[\mathrm{Na}^{+}\right]_{i}$ was measured by ratio imaging of the dye SBFI (see Materials and Methods). A, Changes in SBFI ratio are small and short lived for $50 \mathrm{~K}$ salinc application $(10 \mathrm{sec})$ compared to $\mathrm{KA}$ application $(200 \mu \mathrm{M}, 5 \mathrm{sec})$. Record is the average of three neurons. $B$, KA application $(5 \mathrm{sec})$ in $\mathrm{Ca}^{2+}$-free saline produces a rise in $\left[\mathrm{Na}^{+}\right]_{i}$ whose recovery is hastened by change to $\mathrm{Na}^{+}$-free $\left(\mathrm{Ca}^{2+}\right.$-containing) saline. KA application in $\mathrm{Na}^{+}$-free saline produced no change in $\left[\mathrm{Na}^{+}\right]_{i}$. The rate of recovery following KA application in normal saline is slower than in $\mathrm{Ca}^{2+}$-free saline, suggesting $\mathrm{Ca}^{2+}$ entry slows the rate of recovery. Record is the average of responses in seven neurons. $C$, Multiple KA applications $(2.5 \mathrm{sec})$ in $\mathrm{Ca}^{2+}$-free and normal saline reveal that increase of the integral of the rise in $\left[\mathrm{Na}^{+}\right]_{i}$ is not due to order of treatment (average of eight neurons). Increased duration of $[\mathrm{Na}+]_{i}$ imbalance is reproducibly produced by $\mathrm{Ca}^{2+}$ coentry during $\mathrm{KA}$ stimulation. 

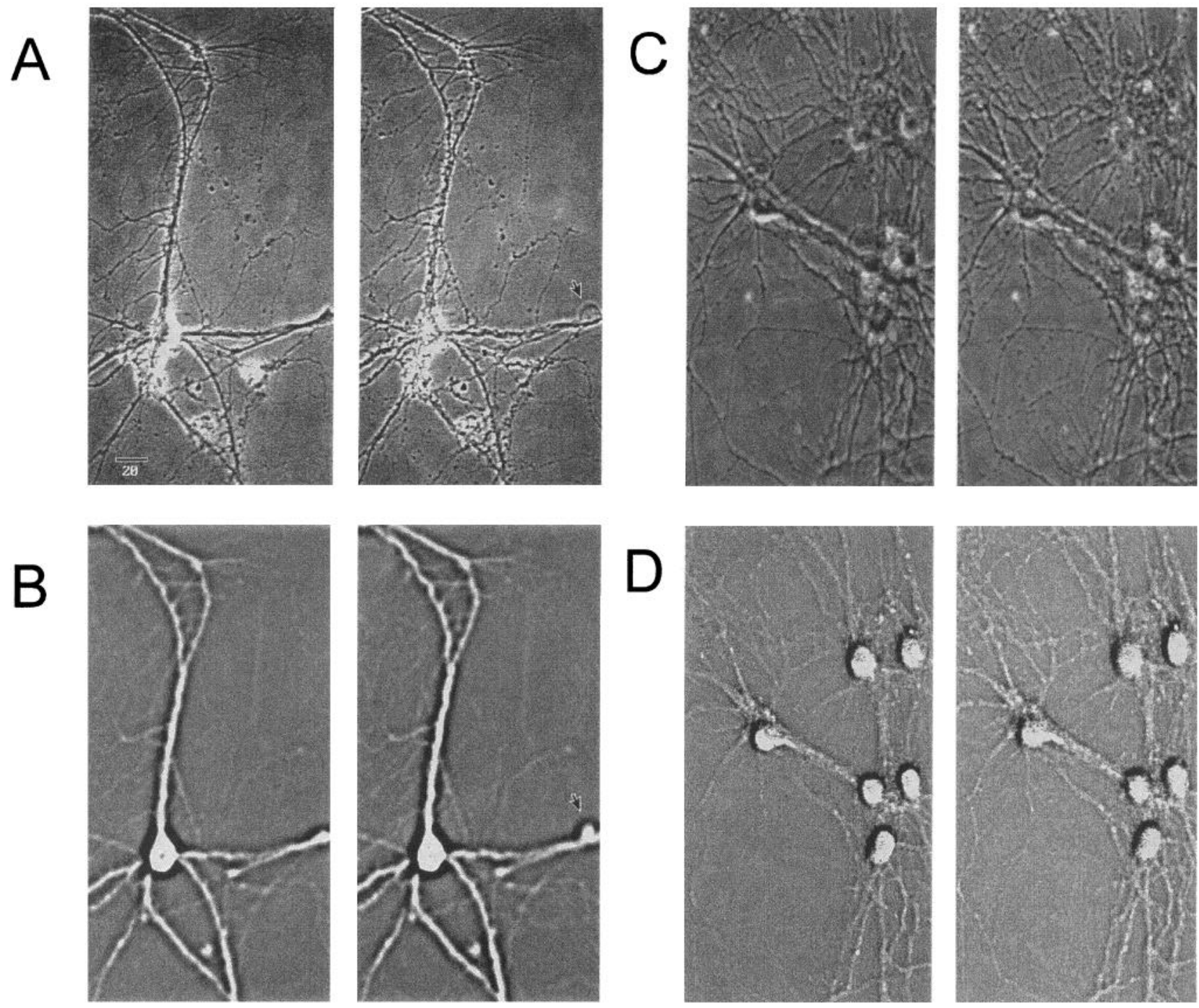

Figure 5. Treatment of cerebellar neurons with $\mathrm{Ca}^{2+}$ or $\mathrm{Na}^{+}$ionophores does not produce localized bleb formation. A, Application of 4-Br-A23187 $(4 \mu \mathrm{M})$ increased $\left[\mathrm{Ca}^{2+}\right]_{i}$ to high levels and produced uniform swelling of the soma and neurites as well as neurite degeneration, but rarely produced blister-like blebs. The increases in $\left[\mathrm{Ca}^{2+}\right]_{i}$ were spatially uniform (data not shown). Images in $A$ and $C$ are phase contrast. Right panel was obtained $30 \mathrm{~min}$ after ionophore application. Note that only a single, blister-like bleb is evident (arrow), an exceptional event. Overall, only three blebs were observed to form in 12 neurons (six experiments) despite the presence of numerous neurite intersections. $B$, Digitally processed images of fura-2 fluorescence $(\mathrm{Ex}=380 \mathrm{~nm})$ taken at similar time points as panels in $A$ also demonstrate the single bleb that formed. $C$, Application of gramicidin $\mathrm{D}(5 \mu \mathrm{M})$ equilibrated the $\left[\mathrm{Na}^{+}\right]$across the cell membrane (data not shown) resulting in uniform swelling and degeneration (disruption/condensation) of neurites, but not bleb formation. Phase-contrast image on right was obtained $30 \mathrm{~min}$ after ionophore. $D$, Corresponding digitally processed images of fura-2 fluorescence $(E x=380 \mathrm{~nm})$ for panels in $C$ demonstrate smooth neurite contours and swollen somas. Data are representative of 13 neurons in three experiments.

neurite intersections $(74$ of 88 blebs $=84 \%)$. After $10-20 \mathrm{~min}$ of $\mathrm{Ca}^{2+}$ removal, glutamate receptor activation was often able to produce bleb formation. An immediate rise in $\left[\mathrm{Ca}^{2+}\right]_{i}$ occurred within blebs after change to KA in regular saline, suggesting these sites had a high $\mathrm{Ca}^{2+}$ permeability. Subsequently, new blebs formed in 7 of 14 preparations ( 48 of $50=96 \%$ blebs at neurite intersections) and existing blebs burst in 3 of 14 preparations.

\section{Changes In $\left[\mathrm{Na}^{+}\right]_{\mathrm{i}}$}

We therefore compared the effects of kainate stimulation on $\left[\mathrm{Na}^{+}\right]_{i}$, the other main cation that enters KA-gated channels. Participation of $\mathrm{Na}^{+}$in bleb formation was also suggested by the observation that blebs formed after KA applications in $\mathrm{Na}^{+}-$ free saline increased rapidly in volume upon return to normal $\mathrm{Na}^{+}$-containing saline (data not shown). We did not attempt to map $\mathrm{Na}^{+}$entry points precisely due to the relatively narrow change in SBFI ratios as compared to that of fura 2. Due to the lower signal-to-noise ratio $\left[\mathrm{Na}^{+}\right]_{i}$ data were obtained only for the cell somas and not neurites. We expect $\left[\mathrm{Na}^{+}\right]_{i}$ regulation is similar in dendrites and the soma.

Mean resting $\left[\mathrm{Na}^{+}\right]_{i}$ was $14 \pm 1 \mathrm{mM}(n=42)$ and increased to a peak of $107 \pm 7 \mathrm{~mm}(n=13)$ after a $2.5 \mathrm{sec}$ application of KA $(200 \mu \mathrm{M})$ in normal saline. Prolonged KA applications (10-20 min) could completely dissipate the $\mathrm{Na}^{+}$gradient (data not shown). $\left[\mathrm{Na}^{+}\right]_{i}$ increases resulting from depolarizations with 

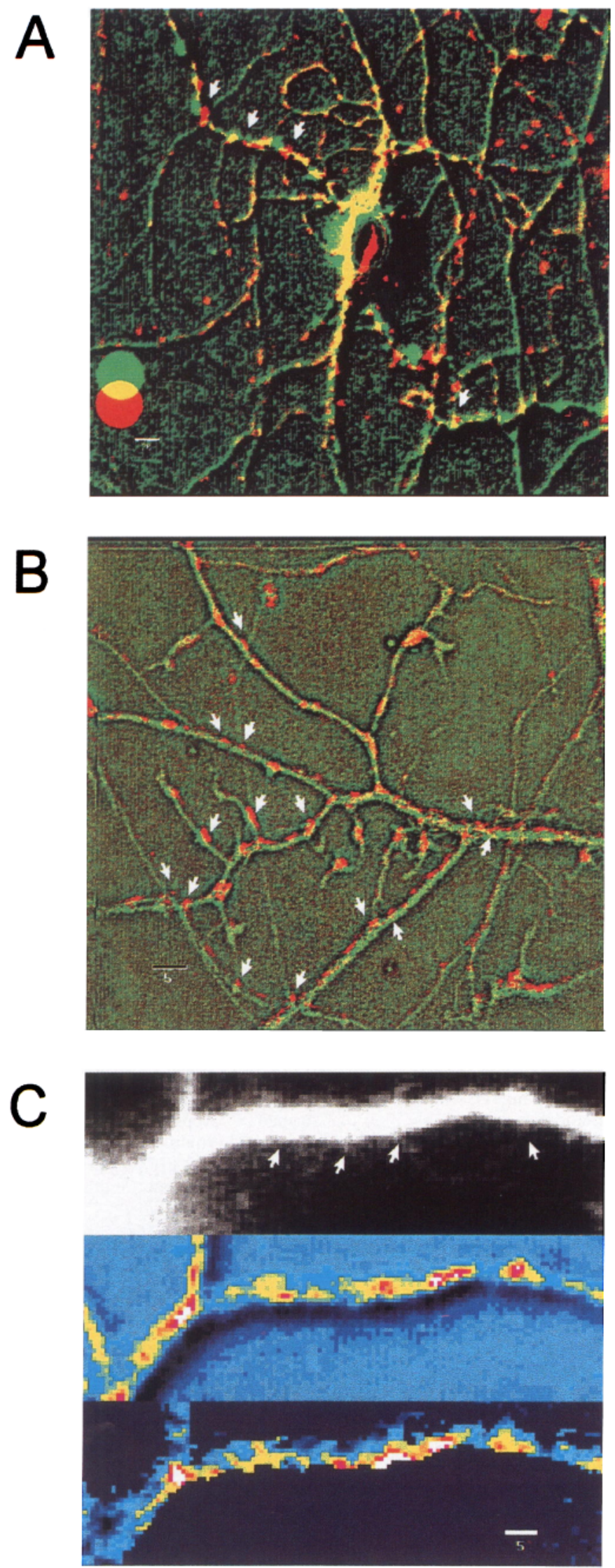

$50 \mathrm{~K}$ were much smaller in amplitude and duration compared to those produced by KA in normal saline (Fig. 4A). This may be due to the rapid inactivation of voltage-gated $\mathrm{Na}^{+}$channels versus prolonged permeation through glutamate-gated channels (Kiedrowski et al., 1993a,b). In addition, the recovery time of resting $\left[\mathrm{Na}^{+}\right]_{i}$ produced by brief $\mathrm{KA}$ applications was dependent on the duration of KA stimulation and also on the cations present during KA application. For example, in saline with $0 \mathrm{mM}\left[\mathrm{Ca}^{2+}\right]_{o}$ the width at half-height for $\mathrm{Na}^{+}$rises resulting from $2.5 \mathrm{sec}$ and $5 \mathrm{sec}$ KA applications was $94.5 \pm 9.5 \mathrm{sec}(n=7)$ and 175.9 $\pm 15.3 \mathrm{sec}(n=12)$, respectively. Furthermore, coentry of $\mathrm{Ca}^{2+}$ with $\mathrm{Na}^{+}$that occurred in normal saline prolonged the duration of the KA-gated rise in $\left[\mathrm{Na}^{+}\right]_{i}$ (Fig. $4 B$ ). For 5 sec KA applications the $1 / 2$ width for the $\left[\mathrm{Na}^{+}\right]_{i}$ rise significantly increased from $167 \pm 18 \mathrm{sec}$ in $\mathrm{Ca}^{2+}$-free saline to $346 \pm 49 \mathrm{sec}(n=7$; $p=0.002$, paired $t$ test) when both $\mathrm{Na}^{+}$and $\mathrm{Ca}^{2+}$ were available to enter the neurons. As shown in Figure $4 C$, this was not due to the order of application since double KA (2.5 sec) applications in $\mathrm{Ca}^{2+}$ - free saline (allowing only $\mathrm{Na}^{+}$entry) and in normal saline $\left(\mathrm{Ca}^{2+}\right.$ plus $\mathrm{Na}^{+}$entry permitted) were not different within each saline condition $(p>0.05)$. However, both KA applications in normal saline had significantly prolonged the half-widths for the $\mathrm{Na}^{+}$rise (from 88 to $131 \mathrm{sec} ; p<0.05$; repeated measures ANOVA; $n=7$ ). These data suggest that $\mathrm{Ca}^{2+}$ entry inhibits recovery of $\mathrm{Na}^{+}$homeostasis following KA stimulation.

\section{Are local changes in ion concentrations responsible for blebbing?}

Given the close correlation of blebs with initial peaks in $\left[\mathrm{Ca}^{2+}\right]_{i}$ increases, we next investigated if blebs could form in association with uniform increases in $\mathrm{Ca}^{2+}$ and $\mathrm{Na}^{+}$mediated by ionophores. Prolonged application (10-20 min) of the $\mathrm{Ca}^{2+}$ ionophore, 4- $\mathrm{Br}$ A23187, produced increases in $\left[\mathrm{Ca}^{2+}\right]_{i}$ that equaled or exceeded

\section{$\leftarrow$}

Figure 6. Bleb sites are rich in RH-414 signals and mitochondria. A, Staining pattern (red signal) after application of RH-414 (30 $\mu \mathrm{M}$ in 50 $\mathrm{mm} \mathrm{K} \mathrm{K}^{+}$saline; $1 \mathrm{~min}$ ) is punctate and abundant along neurites. $\mathrm{RH}-414$ is reported to stain synaptic vesicles in an activity-dependent manner (Betz et al., 1992). The green background image is the fura- 2 emission following bleb formation and is the same cell shown in Figure 2. Note that many RH-414 regions are located at neurite intersections and blebs (green swellings; arrows) are typically associated with intense RH-414 sites. Regions of overlap are yellow (color circles lower left: red + green $=$ yellow). $B$, Digitally filtered image of rhodamine-123 emission following $2 \mathrm{~min}$ staining $(10 \mu \mathrm{g} / \mathrm{ml})$ reveals a nonuniform pattern (red overlay). Image is registered onto similarly processed fluorescence image of fura-2 (Ex $340 \mathrm{~nm}$ ) with a small offset to aid viewing the R123 signal. Numerous mitochondria are located sporadically in fine processes and large clusters of mitochondria (arrows) often occur at neurite intersections but are located in other regions as well. $C$, Mitochondria are associated with many of the loci of the initial rise in $\left[\mathrm{Ca}^{2+}\right]_{i}$ produced by KA. Top is the raw fura-2 image (Ex $380 \mathrm{~nm}$ ) showing the neurite with a branch point (left) and intersections with barely visible axon-like neurites (arrows). Middle panel is a pseudocolored image of R123 intensity showing a punctate distribution of mitochondria-rich regions along the dendrite. Warm colors indicate more-intense R123 emission. The bottom panel is the pseudocolored map of $\mathrm{Co}^{2+}$ entry points seen as quench of fura 2 (Ex 340) fluorescence at the instant of $\mathrm{KA}$ application. Image was derived by subtracting fluorescence image taken roughly $10 \mathrm{sec}$ after KA application from control image just prior to application. Brighter regions are due to $\mathrm{Co}^{2+}$ quenching of fluorescence leaving a greater portion of the baseline intensity (see Materials and Methods). Note that the most intense regions are codistributed with the R123 staining (middle panel) and also with neurite intersections (upper panel). Scale bars: $A, 20 \mu \mathrm{m} ; B$ and $C, 5 \mu \mathrm{m}$. 

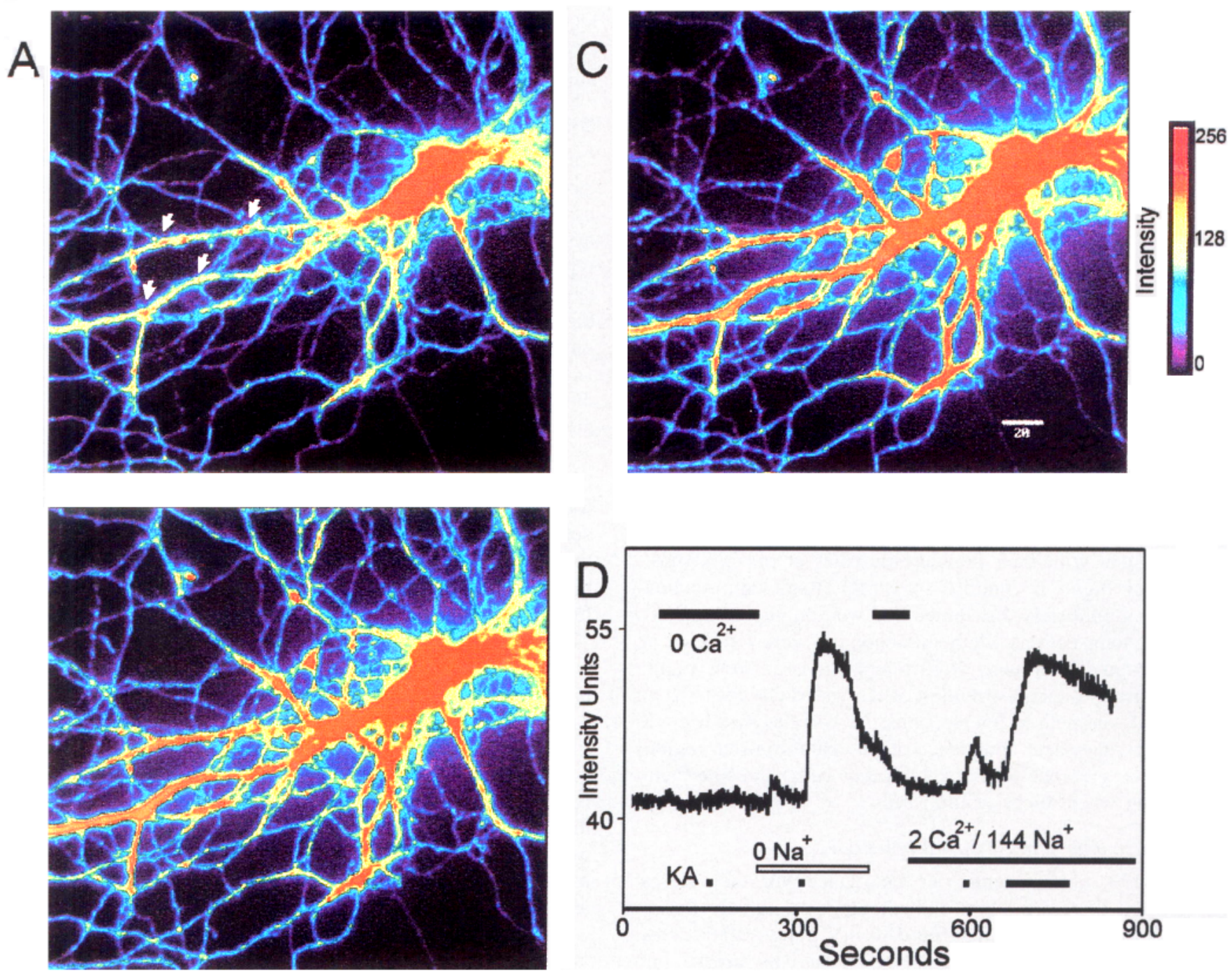

Figure 7. KA application leads to loss of mitochondrial membrane potential. A:Left, Pseudocolored image of R123 staining reveals nonuniform pattern within neurites especially near neurite intersections (e.g., arrows). R123 stains mitochondria according to membrane potential. Sequestration of dye within mitochondria results in intense staining but also causes partial quenching of fluorescence. Collapse of mitochondrial potential releases the dye and an increase in fluorescence. Staining intensity is colorized as indicated by scale. Regions near the soma appear flat-topped due to camera saturation. $B$, Application of $50 \mathrm{~K}$ saline results in an increase in R123 fluorescence and a more uniform distribution of dye. This action is consistent with loss of mitochondrial potential and consequent release of bound dye. $C$, Similar mitochondrial uncoupling is observed after application of KA. $D$, Average plot ( $n=2$ cells) of R123 intensity (mitochondrial potential) showing no loss of dye during KA application (5 sec) in $\mathrm{Ca}^{2+}$-free saline. The reapplication of $\mathrm{Ca}^{2+}$-containing but $\mathrm{Na}^{+}$-free saline results in a small release of $\mathrm{R} 123$. KA application in $\mathrm{Na}^{+}$-free saline releases R123 consistent with $\mathrm{Ca}^{2+}$-mediated uncoupling of mitochondrial potential. A brief $(5 \mathrm{sec})$ application of KA in normal saline produced only a small release of $\mathrm{R} 123$, but a prolonged application again produced a large release of R123. Data are representative of four experiments. Scale bar $(A-C), 20 \mu \mathrm{m}$.

those observed with KA applications; in some cases they exceeded the reporting capacity of fura $2(\geq 1.5 \mu \mathrm{M})$. Neurites appeared to condense and degenerate (break apart), and this was accompanied by swelling of the somas. However, blebs usually did not form. A single exception is indicated in Figure 5A (arrow). As expected, maps of the rise in $\left[\mathrm{Ca}^{2+}\right]_{i}$ following ionophore were very uniform in comparison to that produced by KA (data not shown). Similarly, prolonged loading of cells with $\mathrm{Na}^{+}$using gramicidin produced degeneration and swelling, but not blebbing (Fig. $5 C$ ). It should be noted that these ionophore treatments affect multiple ions since high $\mathrm{Ca}^{2+}$ loading also leads to $\left[\mathrm{Na}^{+}\right]_{i}$ accumulation and $\mathrm{Na}^{+}$loading (by hampering $\mathrm{Na}^{+}-$ requiring exchangers) slowly gives rise to increased $\left[\mathrm{Ca}^{2+}\right]_{i}$ (data not shown). Despite generalized $\mathrm{Ca}^{2+}$ or $\mathrm{Na}^{+}$loads that were equal or higher than those produced by KA treatments, typical blebbing patterns did not form. It is noteworthy that following ionophore wash-out, characteristic blebbing patterns could be generated by subsequent KA treatment (data not shown). These findings suggest that localized ion imbalances may be required for bleb formation.

\section{Properties of neurite intersections}

Contacts at neurite intersections are sites where synapses are likely to form. Consistent with this notion, many of the intersections stained (Fig. 6A) with the styryl dye, RH-414, reported to stain synaptic vesicles in a use-dependent manner (Betz et al., 1992). The RH414 sites were confirmed to be regions rich in synaptic vesicles by immunostaining fixed preparations for syn- 
aptophysin (data not shown). Numerous RH-414/synaptophysinpositive regions were also observed along neurites suggesting fasciculation of neurites and presence of en passant-type synapses. In addition, cell somas were usually rich in RH414 regions. In a sample of four images, 75 of 79 blebs formed after KA application were associated with RH414 sites. However, most RH414 sites were not associated with blebs formed 20-45 min after onset of KA exposure (1743 of 1818 sites; $96 \%$ ). Thus, the abundance of stained regions over all regions of the neurites and soma suggested that putative synapses did not predict bleb formation sites yet blebs were associated with a subset of these synapses. It should be noted that these staining methods do not differentiate excitatory and inhibitory synapses, nor the efficacy of synapses. Moreover, the lack of a RH414 site on a bleb cannot be interpreted as proof that no synapse was present. Since blebs tended to form at regions associated with peak rises in KA-gated increases in $\left[\mathrm{Ca}^{2+}\right]_{i}$ only a subset of synaptic-vesicle-rich sites were able to promote bleb formation, perhaps the strongest excitatory synapses.

Mitochondria were also usually abundant at neurite intersections consistent with their homeostatic roles at pre- and postsynaptic loci. Figure 6, $B$ and $C$ shows R123-stained mitochondria were nonuniformly distributed and were highly colocalized with neurite intersections. Many mitochondria were visible along fine neurites and well away from intersections as well. Figure $6 C$ demonstrates the codistribution of $\mathrm{KA}$-gated $\mathrm{Co}^{2+}$ entry loci, R123 signal, and neurite intersections. As was the case for synaptic regions, the sheer abundance of mitochondria-rich regions precluded the presence of mitochondria as being the sole factor in predicting where blebs would form.

\section{Calcium uncouples mitochondrial potential}

The dye R123 stains structures in accordance with their Nernst potential and therefore stains mitochondria selectively due to their potential normally being $160-180 \mathrm{mV}$ more negative than the cytoplasm. The dye is partially quenched by uptake into mitochondria (Emaus et al., 1986). Collapse of this potential by mitochondrial uncouplers leads to release of the dye, an increase in fluorescence, and if depolarization is prolonged, eventual loss of the dye (Duchen and Biscoe, 1992). Application of $50 \mathrm{~K}$ or $\mathrm{KA}$ produced an increase in fluorescence as well as a change from a punctate to a diffuse staining pattern (Fig. $7 A-C$ ). In $\mathrm{Ca}^{2+}$-free solutions KA produced no change in mitochondrial potential (Fig. 7D). Upon return to $\mathrm{Ca}^{2+}$-containing but $\mathrm{Na}^{+}$-free saline, the fluorescence increased briefly, an action consistent with activation of reverse-mode $\mathrm{Na} / \mathrm{Ca}$ exchange. $\mathrm{KA}$ application in $\mathrm{Na}^{+}$-free, $\mathrm{Ca}^{2+}$-containing saline produced a large increase in fluorescence indicating a loss of mitochondrial membrane potential. When KA was applied in normal saline the loss of mitochondrial potential was reduced, suggesting that a $\mathrm{Na}^{+}$dependent process (probably $\mathrm{Na} / \mathrm{Ca}$ exchange) eliminated much of the $\mathrm{Ca}^{2+}$ before it could reach and uncouple mitochondria. A prolonged KA application fully collapsed the $\mathrm{Na}^{+}$gradicnt (data not shown), inhibited $\mathrm{Na} / \mathrm{Ca}$ exchange, and again produced mitochondrial depolarization.

Mitochondrial potential is absolutely related to the ability to oxidatively produce ATP. Even a depolarization from -180 to $-120 \mathrm{mV}$ can be sufficient to make oxidative phosphorylation thermodynamically unfeasible (Berry et al., 1988). While both $50 \mathrm{~K}$ and $\mathrm{KA}$ increase $\left[\mathrm{Ca}^{2+}\right]_{i}$ and can depolarize mitochondria, it is also clear that the $\left[\mathrm{Ca}^{2+}\right]_{i}$ is buffered much more quickly under the $50 \mathrm{~K}$ case (Figs. 4,7 ). Thus, the duration of depolar- ization and inhibition of oxidative ATP generation might be longer in the KA case. This may be related to the typically greater ability of KA to produce excitotoxicity in this preparation.

\section{Discussion}

Cultures of cerebellar neurons enriched in Purkinje-like cells have been shown to be highly susceptible to excitotoxic damage by AMPA-receptor agonists (Brorson et al., 1994). Stimulation of glutamate receptors with kainic acid (KA) leads to cell death typified by swelling of cell somas and nonuniform swelling of dendrites ("blebbing"). The main finding of these studies is that blebs formed non-randomly on dendrites exhibiting the highest rises in $\left[\mathrm{Ca}^{2+}\right]_{i}$ suggesting the presence of a high density of voltage-gated $\mathrm{Ca}^{2+}$ channels and glutamate-gated channels. Specifically, the vast majority (approximately 80\%) of blebs formed at neurite intersections (Figs. 1-3). In addition, the initial sites of $\left[\mathrm{Ca}^{2+}\right]_{i}$ elevations stimulated by KA appeared to have a punctate pattern and effectively predicted where over $80 \%$ of blebs formed tens of minutes later (Figs. 2, 3, 6). Recent reports have demonstrated that both voltage-sensitive $\mathrm{Ca}^{2+}$ channels and glutamate receptors can be spatially clustered on neurons (Hockberger et al., 1989; Westenbroek et al., 1990; Craig et al., 1993; Froehner, 1993; Jaffe et al., 1994; Manilow et al., 1994; etc.). The $\mathrm{Ca}^{2+}$ entry sites typically corresponded to regions of close contact between neurites. Where contacts were not elaborate, no $\left[\mathrm{Ca}^{2+}\right]_{i}$ rises were observed and no blebs formed (e.g., Figs. 2, 3 ). The relationship between bleb loci, ion entry sites, and neurite intersections was investigated in greater detail.

Since blebs normally formed within neurites that had rises in $\left[\mathrm{Ca}^{2+}\right]_{i}$ and were most often associated with regions showing the highest initial rises in $\left[\mathrm{Ca}^{2+}\right]_{i}$ a $\mathrm{Ca}^{2+}$ requirement for bleb formation seems likely. On the other hand, blebs did not always form at points of high $\left[\mathrm{Ca}^{2+}\right]_{i}$, indicating that other factors must also play a role.

Since $\mathrm{Na}^{+}$readily permeates AMPA receptors, we therefore also measured changes in $\left[\mathrm{Na}^{+}\right]_{i}$. Bleb formation sometimes occurred following $\mathrm{KA}$ exposure in $\mathrm{Ca}^{2+}$-free saline. While we could not resolve the entry patterns for $\mathrm{Na}^{+}$in neurites, we expect the punctate pattern seen for $\mathrm{Ca}^{2+}$ (and $\mathrm{Co}^{2+}$ ) also results in initially punctate $\mathrm{Na}^{+}$loading. Following $5 \mathrm{sec}$ exposures to $\mathrm{KA},\left[\mathrm{Na}^{+}\right]_{i}$ rose to very high concentrations for several minutes, similar to the cases recently reported by Kiedrowski et al. (1993a,b) for hippocampal and cerebellar granule neurons. The integral of the $\mathrm{Na}^{+}$rise following brief $\mathrm{KA}$ applications under $\mathrm{Ca}^{2+}$-free conditions was significantly smaller than for cases where both $\mathrm{Na}^{+}$and $\mathrm{Ca}^{2+}$ entered the cells (Fig. 4). Since $\mathrm{Na}^{+}$ is not buffered in the cell, this implies that $\mathrm{Ca}^{2+}$ hampers the $\mathrm{Na}^{+}$pump or, in addition, that $\mathrm{Na}^{+}$continues to enter the cell at the expense of $\mathrm{Ca}^{2+}$ removal. The former possibility has been demonstrated for $\mathrm{Na} / \mathrm{K}$ ATPases isolated from various rat tissues (McGeoch, 1990) and has been suggested to occur in rat hippocampal neurons (Fukuda and Prince, 1992). The prolongation of elevated $\left[\mathrm{Na}^{+}\right]_{i}$ due to the action of the $\mathrm{Na} / \mathrm{Ca}$ cxchanger has recently been observed in hippocampal neurons and cerebellar granule cells (Kiedrowski et al., 1993a,b). In these ways locally high $\left[\mathrm{Ca}^{2+}\right]_{i}$ could maintain $\left[\mathrm{Na}^{+}\right]_{i}$ high enough and long enough to foster bleb formation. In addition, $\mathrm{Ca}^{2+}$-activated chloride channels should be open under conditions of elevated $\left[\mathrm{Ca}^{2+}\right]_{i}$ (Llano et al., 1991). If $\mathrm{Cl}^{-}$follows the elevated $\left[\mathrm{Na}^{+}\right]_{i}$, and water follows both, then local swelling will occur.

If activation of some process leading to cell death is limited to certain neurite intersections, why then do blebs typically not 
form if the ionic conditions are simulated by ionophore treatments? Indeed, raising $\left[\mathrm{Ca}^{2+}\right]_{i}$ with $4-\mathrm{Br}-\mathrm{A} 23187$ or $\left[\mathrm{Na}^{+}\right]_{i}$ with gramicidin to average levels exceeding those created by KA application lead to cell swelling but not bleb formation (Fig. 5). Bleb-promoting factors presumed to be localized at neurite intersections should have been activated under these conditions. Since blebbing did not normally occur, the ionophores may not have precisely mimicked the ionic conditions produced during glutamate receptor stimulation. Clustered ion channels at synaptic sites are expected to produce microdomains of elevated $\left[\mathrm{Ca}^{2+}\right]_{i}$ that exceed the reporting capacity of fura 2 (Llinás et al., 1992). Thus, while average ion concentrations during ionophore applications may appear similar to those observed with KAinduced blebbing, the lack of such microdomains may explain why blebs did not form following ionophore treatment. This hypothesis is supported by the similar potency of BAPTA derivatives with widely ranging $\mathrm{Ca}^{2+}$-chelating abilities $\left(K_{d}\right.$ range $100 \mathrm{nM}$ to $3.6 \mu \mathrm{M})$ in ameliorating excitotoxic cell death presumably by limiting $\left[\mathrm{Ca}^{2+}\right]_{i}$ within microdomains (Tymianski et al., 1993b).

How might higher $\left[\mathrm{Ca}^{2+}\right]_{t}$ signals at microdomains be linked with production of blebs? The answer may be related to high mitochondrial density at those points. Our data show loss of mitochondrial potential during stimulation with $\mathrm{KA}$ is linked to $\mathrm{Ca}^{2+}$ and not $\mathrm{Na}^{+}$entry (Fig. 7). Perhaps blebbing is initiated by prolonged cation flux at microdomains where $\left[\mathrm{Ca}^{2+}\right]_{i}$ uncouples mitochondria and activates/ inhibits other local processes. $\Lambda$ key element controlling whether events will lead to bleb formation and subsequent cell demise may be the loss of normal mitochondrial function. Mitochondria are appropriately positioned at postsynaptic sites in order to supply ATP for maintaining ionic homeostasis. The close correspondence between R123-stained sites and KA-gated $\mathrm{Ca}^{2+}$ entry patterns (Fig. $6 C$ ) supports the codistribution of mitochondria and synaptic regions in the cerebellar neurons used in present studies. $\mathrm{Ca}^{2+}$ is known to regulate the rate of oxidative phosphorylation so that $\mathrm{Ca}^{2+}$ entry under normal synaptic activity balances ATP production with need for ionic homeostasis (cf. McCormack et al., 1990; Gunter et al., 1994). Under conditions associated with pathological $\left[\mathrm{Ca}^{2+}\right]_{i}$ overload, the high $\left[\mathrm{Ca}^{2+}\right]_{i}$ presumably uncouples the mitochondria and perhaps forces a greater reliance of ATP production by glycolysis. Indeed recovery of ionic homeostasis has been observed to depend more on glycolysis than oxidative phosphorylation after treatment with $\mathrm{Ca}^{2+}$ ionophore (Kristensen, 1993). If $\mathrm{Ca}^{2+}$ enters quickly at microdomains, perhaps before $\mathrm{Mg}^{2+}$ released by ATP utilization inhibits mitochondrial $\mathrm{Ca}^{2+}$ uptake and released $\mathrm{P} i$ aids restoration of mitochondrial potential (cf. Carafoli, 1979; Nicholls and Åkerman, 1982), then large $\mathrm{Ca}^{2+}$ accumulations by mitochondria may result in damage. Mitochondrial depolarization by local elevations in $\left[\mathrm{Ca}^{2+}\right]_{i}$ has been recently demonstrated (Rizzuto et al., 1993; Loew et al., 1994). Collapse of mitochondrial potential is also linked with bleb formation in hepatocytes (Nieminen et al., 1990). The high $\left[\mathrm{Ca}^{2+}\right]_{i}$ and $\left[\mathrm{Na}^{+}\right]_{i}$ we observed after prolonged $\mathrm{KA}$ applications are similar to those conditions required for enhanced production of oxygen free radicals observed to occur in isolated cerebellar and cerebral mitochondria (Dykens, 1994). Indeed, preliminary observations indicate a nonuniform generation of superoxide anions occurs in what appear to be mitochondria within cerebellar neuron dendrites, especially after stimulation with KA (Bindokas and Miller, unpublished data). Free radicals may further impair mitochondrial complex-1 activity as well as numerous key met- abolic enzymes (cf. Dykens, 1994). Elevated $\left[\mathrm{Ca}^{2+}\right]_{i}$ in the presence of oxygen radicals may activate the mitochondrial permeability transition pore (Valle et al., 1993), an event recently suggested to be involved in routine releases of mitochondrial $\mathrm{Ca}^{2+}$ (Ichas et al., 1994). The increase in $\left[\mathrm{Ca}^{2+}\right]_{i}$ may also stimulate nitric oxide synthase that is abundant in cerebellum (reviewed in Dawson and Snyder, 1994) producing nitric oxide which readily combines with endogenous superoxide to form the powerful oxidant peroxynitrite (cf. Packer and Murphy, 1994). Superoxide and peroxynitrite inhibit the mitochondrial enzyme aconitase (Castro et al., 1994; Hausladen and Fridovich, 1994). Peroxynitrite activates $\mathrm{Ca}$ efflux via the mitochondrial permeability transition pore (Packer and Murphy, 1994) and inhibits electron transport (Radi et al., 1994). Thus, the large-scale changes in local ionic gradients might promote conditions leading to loss of the major source of ATP and perhaps ability to maintain ionic homeostasis.

The idea that $\left[\mathrm{Ca}^{2+}\right]_{i}$ must only accumulate sufficient local concentrations to uncouple mitochondria or initiate other events may explain why variable thresholds in average $\left[\mathrm{Ca}^{2+}\right]_{i}$ are associated with initiation of degeneration. While the total $\mathrm{Ca}^{2+}$ load has been shown to predict cell death (e.g., Hartley et al., 1993), the pattern of $\mathrm{Ca}^{2+}$ entry also appears critical for inducing progression to death (Tymianski, 1994). Mitochondrial impairments are implicated in various neuronal degenerative diseases and increased susceptibility to excitotoxic damage (e.g., Beal, 1992). The duration and degree of loss of cellular energy production may determine whether a $\mathrm{Ca}^{2+}$ load leads to death or recovery. Indeed, bleb formation in rat hepatocytes during chemical hypoxia was directly correlated with ATP concentration (Harman et al., 1990). We have occasionally observed formation of blebs following KA treatment in $\mathrm{Ca}^{2+}$-free saline in neurons with poor health (granular, vacuolated cytoplasm) and perhaps illustrates the ease of homeostatic disruption under conditions of compronised energy production (data not shown). ATP levels in such cells may be already sufficiently low to permit the $\mathrm{Na}^{+}$ entering glutamate-gated ionophores to produce blebbing at the characteristic loci. Both low and excessive $\left[\mathrm{Ca}^{2+}\right]_{i}$ hamper ATP production.

In summary, our data indicate that ionic homeostasis is first lost in regions where local overload of $\mathrm{Ca}^{2+}$ (and presumably $\mathrm{Na}^{+}$) occurs following AMPA receptor activation. The speed of cation flux and the proximity of $\left[\mathrm{Ca}^{2+}\right]_{i}$ microdomains to mitochondria may be critical requirements for initiation of localized damage in neurites given the relative ineffectiveness of ionophores to induce blebs. It appears that local extremes in ion concentrations promote conditions required for bleb formation. Blebs thus appear to be manifestations of local ionic and energetic imbalance and that under severe conditions may produce a loss of membrane integrity at these sites. While it is conceivable that overactivation of glutamate receptors activates some unknown process apart from changes in ionic concentrations that somehow activates degeneration, the present observations of clustered ion channels initiating local ionic imbalances at mitochondria-rich loci appear to be sufficient to explain the local formation of blebs in many instances.

\section{References}

Beal MF (1992) Does impairment of energy metabolism result in excitotoxic neuronal death in neurodegenerative illness? Ann Neurol 31:119-130.

Berry MN, Gregory RB, Grivell AR, Henly DC, Nobes CD, Phillips JW, Wallace PG (1988) Intracellular mitochondrial membrane po- 
tential as an indicator of hepatocyte energy metabolism: further evidence for thermodynamic control of metabolism. Biochem Biophys Acta 936:294-306.

Betz WJ, Mao F, Bewick GS (1992) Activity-dependent fluorescent staining and destaining of living vertebrate motor nerve terminals. $\mathrm{J}$ Neurosci 12:363-375.

Bindokas VP, Bleakman D, Miller RJ (1993) Spatial patterns of calcium entry into cultured rat cerebellar neurons are correlated with initiation sites for degeneration. Soc Neurosci Abstr 19:1333.

Bindokas VP, Brorson JR, Miller RJ (1993) Characteristics of voltage sensitive calcium channels in dendrites of cultured rat cerebellar neurons. Neuropharmacology 32:1213-1220.

Bleakman D, Chard PS, Foucart S, Miller RJ (1991) Block of neuronal $\mathrm{Ca}^{++}$influx by the anti-ischemic agent TA3090. J Pharmacol Exp Ther 259:430-438.

Brorson JR, Bleakman D, Gibbons SJ, Miller RJ (1991) The properties of intracellular $\mathrm{Ca}^{2+}$ stores in cultured rat cerebellar neurons. J Neurosci 11:4024-4043.

Brorson JR, Bleakman D, Chard PS, Miller RJ (1993) Calcium directly permeates kainate/ $\alpha$-amino-3-hydroxy-5-methyl-4-isoxazolepropionic acid receptors in cultured cerebellar Purkinje neurons. Mol Pharmacol 41:603-608.

Brorson JR, Manzolillo PA, Miller RJ (1994) $\mathrm{Ca}^{2+}$ entry via AMPA/ KA receptors and excitotoxicity in cultured cerebellar Purkinje cells J Neurosci 14:187-197.

Burton KP, Morris AC, Massey KD, Buja LM, Hagler HK (1990) Free radicals alter ionic calcium levels and membrane phospholipids in cultures rat ventricular myocytes. J Mol Cell Cardiol 22:1035-1047.

Carafoli E (1979) The calcium cycle of mitochondria. FEBS Lett 104: $1-5$.

Castro L, Rodriguez M, Radi R (1994) Aconitase is readily inactivated by peroxynitrite, but not by its precursor, nitric oxide J. Biol Chem 269:29409-29415.

Choi DW (1988) Glutamate neurotoxicity and diseases of the nervous system. Neuron 1:623-634.

Choi, DW (1992) Excitotoxic cell death. J Neurobiol 23:1261-1276.

Craig AM, Blackstone CD, Huganir RL, Banker G (1993) The distribution of glutamate receptors in cultured rat hippocampal neurons: postsynaptic clustering of AMPA-selective subunits. Neuron 10 $1055-1068$.

Dawson TM, Snyder SH (1994) Gases as biological messengers: nitric oxide and carbon monoxide in the brain. J Neurosci 14:5147-5159.

Dessi F, Charriaut-Marlangue C, Ben-Ari Y (1994) Glutamate-induced neuronal death in cerebellar culture is mediated by two distinct components: a sodium-chloride component and a calcium component. Brain Res 650:49-55.

Dubinsky JM, Rothman SM (1991) Intracellular calcium concentrations during "chemical hypoxia" and excitotoxic neuronal injury. J Neurosci 11:2545-2551.

Duchen MR, Biscne TJ (1992) Relative mitochondrial membrane potential and $\left[\mathrm{Ca}^{2+}\right]_{i}$ in type I cells isolated from the rabbit carotid body. J Physiol (Lond) 450:33-61.

Dykens JA (1994) Isolated cerebral and cerebellar mitochondria produce free radicals when exposed to elevated $\mathrm{Ca}^{2+}$ and $\mathrm{Na}^{+}$: implications for neurodegeneration. J Neurochem 63:584-591.

Emaus RK, Grunwald R, Lemasters JJ (1986) Rhodamine 123 as a probe of transmembrane potential in isolated rat-liver mitochondria: spectral and metabolic properties. Biochim Biophys Acta 850:436448.

Florine-Casteel K, Lemasters JJ, Hernam B (1991) Lipid order in hepatocyte plasma membrane blebs during ATP depletion measured by digitized video fluorescence polarization microscopy. FASEB J 5:2078-2084.

Friedman JE, Haddad GG (1993) Major differences in $\mathrm{Ca}^{2+}$, response to anoxia between neonatal and adult rat CA1 neurons: role of $\mathrm{Ca}^{2+}$ 。 and $\mathrm{Na}^{+}$. $\mathrm{J}$ Neurosci 13:63-72.

Friedman JE, Haddad GG (1994) Removal of extracellular sodium prevents anoxia-induced injury in freshly-dissociated rat CA1 hippocampal neurons. Brain Res 641:57-64.

Froehner SC (1993) Regulation of ion channel distribution at synapses. Annu Rev Neurosci 16:347-368.

Fukuda A, Prince DA (1992) Excessive intracellular $\mathrm{Ca}^{2+}$ inhibits glutamate-induced $\mathrm{Na}^{+}-\mathrm{K}^{+}$pump activation in rat hippocampal neurons. J Neurophysiol 68:28-35.

Gabai VL, Seilanov AS, Makarova YM, Mosin AF (1990) Oxidative stress, disturbance of energy balance, and death of ascites tumour cells under menadione (vitamin K3) action. Biomed Sci 1:407-413.

Gunter TE, Gunter KK, Sheu S-S, Gavin CF, (1994) Mitochondrial calcium transport: physiological and pathological relevance. Am J Physiol (Cell Physiol 36):C313-C339.

Harman AW, Nieminen A-L, Lemasters JL, Herman B (1990) Cytosolic free magnesium, ATP, and blebbing during chemical hypoxia in cultures rat hepatocytes. Biochem Biophys Res Comm 170:477-483.

Hausladen A, Fridovch I (1994) Superoxide and peroxynitrite inactivate aconitases, but nitric oxide does not. J Biol Chem 269:2940529408

Ichas F, Jouaville LS, Sidash SS, Mazat J-P, Holmuhamedov EL (1994) Mitochondrial calcium spiking: a transduction mechanism based on calcium-induced permeability transition involved in cell calcium signaling. FEBS Lett 348:211-215.

Jaffe DB, Ross WN, Lisman JE, Lasser-Ross N, Miyakawa M, Johnston D (1994) A model for dendritic $\mathrm{Ca}^{2+}$ accumulation in hippocampal pyramidal neurons based on fluorescence imaging measurements. $J$ Neurophysiol 71:1065-1077.

Jewell SA, Bellono G, Thor $\mathbf{H}$, Orrenius S, Smith M (1982) Bleb formation in hepatocytes during drug metabolism is caused by disturbances in thiol and calcium ion homeostasis. Science 217:12571259.

Jurkowitz-Alexander MS, Altschuld RA, Hohl CM, Johnson JD, McDonald JS, Simmons TD, Horrocks LA (1992) Cell swelling, blebbing, and death are dependent on ATP depletion and independent of calcium during chemical hypoxia in a glial cell line (ROC-1). J Neurochem 59:344-352.

Kiedrowski L, Brooker G, Costa E, Wroblewski JT (1993a) Glutamate impairs neuronal calcium extrusion while reducing sodium gradient. Neuron 12:295-300.

Kiedrowski L, Wroblewski JT, Costa E (1993b) Intracellular sodium concentration in cultured cerebellar granule cells challenged with glutamate. Mol Pharmacol 45:1050-1054.

Kristensen SR (1993) Removal of calcium overload caused by A23187 is more dependent on glycolysis than oxidative phosphorylation. Biochim Biophys Acta 1179:23-26.

Kuhne W, Besselmann TN, Noll T, Muhs A, Watanabe H, Piper HM (1993) Disintergration of cytoskeletal structure of actin filaments in energy-depleted endothelial cells. Am J Physiol 264:H1599-H1608.

Loew LM, Carrington W, Tuft RA, Fay FS (1994) Physiological cytosolic $\mathrm{Ca}^{2+}$ transients evoke concurrent mitochondrial depolarizations. Proc Natl Acad Sci USA 91:12579-12583.

Llinás R, Sugimori M, Silver RB (1992) Microdomains of high calcium concentration in a presynaptic terminal. Science 256:677-679.

Llano I, Leresche N, Marty A (1991) Calcium entry increases the sensitivity of cerebellar Purkinje cells to applied GABA and decreases inhibitory synaptic currents. Neuron 6:565-574.

Malorni W, Iosi F, Mirabelli F, Bellomo G (1991) Cytoskeleton as a target in meadione-induced oxidative stress in cultured mammalian cells: alterations underlying surface bleb formation. Chemico-Biol Interact 80:217-236.

Manilow R, Otmakhov N, Blum KI, Lisman J (1994) Visualizing hippocampal synaptic function by optical detection of $\mathrm{Ca}^{2+}$ entry through the $N$-methyl-D-aspartate channels. Proc Natl Acad Sci USA 91:8170-8174.

McCormack JG, Halestrap AP, Denton RM (1990) Role of calcium ions in regulation of mammalian intramitochondrial metabolism. Physiol Rev 70:391-425.

McGeoch JEM (1990) The $\alpha-2$ isomer of the sodium pump is inhibited by calcium at physiological levels. Biochem Biophys Res Commun 30:99-105.

Minta A, Tsien RY (1989) Fluorescent indicators for cytosolic sodium. J Biol Chem 264:19449-19457.

Mirabelli F, Salis A, Marinoni V, Finardi G, Bellomo G, Thor H, Orrenius $S$ (1988) Menadione-induced bleb formation in hepatocytes is associated with the oxidation of thiol groups. Arch Biochem Biophys $264: 261-269$.

Negilescu PA, Harootunian A, Tsien RY, Machen TE (1990) Fluorescence measurements of cytosolic free $\mathrm{Na}$ concentration, influx and efflux in gastric cells. Cell Regul 1:259-268.

Nicholls D, Ảkerman K (1982) Mitochondrial calcium transport. Biochim Biophys Acta 683:57-88.

Nicotera P, Hartzell P, Davis G, Orrenius S (1986) The formation of plasma membrane blebs in hepatocytes exposed to agents that in- 
crease cytosolic $\mathrm{Ca}^{2+}$ is mediated by the activation of non-lysosomal proteolytic system. FEBS Lett 209:139-144.

Nieminen AL, Gores GJ, Dawson TL, Herman B, Lemasters JJ (1990) Toxic injury from mercuric chloride in rat hepatocytes. $J$ Biol Chem 265:2399-2408.

Olney JW, Fuller T, De Gubareff T (1979) Acute dendrotoxic changes in the hippocampus of kainate treated rats. Brain Res 176:91-100.

Packer MA, Murphy MP (1994) Peroxynitrite causes calcium efflux from mitochondria which is prevented by cyclosporin A. FEBS Lett 345:237-240.

Phelps PC, Smith MW, Trump BF (1989) Cytosolic ionized calcium and bleb formation after acute cell injury of cultured rabbit renal tubule cells. Lab Invest 60:630-642.

Peterson C, Neal JH, Cotman CW (1989) Development of $N$-methyl$D$-aspartate excitotoxicity in cultured hippocampal neurons. Dev Brain Res 48:187-195.

Pratt WK (1991) Digital image processing, 2nd Ed, pp 303-305. New York: Wiley.

Pruss RM, Akeson RL, Racke MM, Wilburn JL (1991) Agonist-activated cobalt uptake identifies divalent cation-permeable kainate receptors on neurons and glial cells. Neuron 7:509-518.

Radi R, Rodriguez M, Castro L, Telleri R (1994) Inhibition of mitochondrial electron transport by peroxynitrite. Arch Biochem Biophys 308:89-95.

Rizzuto R, Brini M, Murgia M, Pozzan T (1993) Microdomains with high $\mathrm{Ca}^{2}$ । close to $\mathrm{IP}_{3}$-sensitive channels that are sensed by neighboring mitochondria. Science 262:744-747.

Rothman SM (1985) The neurotoxicity of excitatory amino acids is produced by passive chloride influx. J Neurosci 5:1483-1489.

Scott JA, Fischman AJ, Homey CJ, Fallon JT, Khaw BA, Peto CA, Rabito CA (1989) Free Rad Biol Med 6:361-367.

Sloviter RS, Dempster DW (1985) "Epileptic" brain damage is rep- licated qualitatively in the rat hippocampus by central injection of glutamate or aspartate but not by GABA or acetylcholine. Brain Res Bull 15:39-60.

Toth PT, Bindokas VP, Bleakman D, Colmers WF, Miller RJ (1993) Mechanism of presynaptic inhibition by neuropeptide $Y$ at sympathetic nerve terminals. Nature 364:635-639.

Irump BF, Berezesky IK (1992) 'The role of cytosolic $\mathrm{Ca}^{2+}$ in cell injury, necrosis and apoptosis. Curr Opinion Cell Biol 4:227-232.

Tsai WJ, Chen JC, Wang CT (1988) Changes in both calcium pool size and morphology of human platelets incubated in various concentrations of calcium ion. Calcium-specific bleb formation on platelet-membrane surface. Biochim Biophys Acta 940:105-120.

Tymianski M (1994) Cytosolic calcium concentrations and cell death in vitro. In: Cellular and molecular mechanisms of ischemic damage, pp 1-58. Lund, Sweden: Eric K. Fernström Symposium.

Tymianski M, Charlton MP, Carlen PL, Tator CH (1993a) Source specificity of early calcium neurotoxicity in cultured embryonic spinal ncurons. J Ncurosci 13:2085-2104.

Tymianski M, Wallace MC, Spigelman I, Uno M, Carlen PL, Tator CH, Charlton MP (1993b) Cell-permeant $\mathrm{Ca}^{2+}$ chelators reduce early excitotoxic and ischemic neuronal injury in vitro and in vivo. Neuron $11: 221-235$.

Valle VGR, Fagian MM, Parentoni LS, Meinicke AR, Vercesi AE (1993) Ihe participation of reactive oxygen species and protein thiols in the mechanism of mitochondrial inner membrane permeabilization by calcium plus prooxidants. Arch Biochem Biophys 307:1-7.

Watanabe S, Phillips MJ (1986) Acute phalloidin toxicity in living hepatocytes. Evidence for a possible disturbance in membrane flow and for multiple functions of actin in the liver cell. Am J Pathol 122: 101-111.

Westenbroek RE, Ahlijanian MK, Catterall WA (1990) Clustering of L-type $\mathrm{Ca}^{2+}$ channels at the base of major dendrites in hippocampal pyramidal neurons. Nature 347:281-284. 